\title{
The Effect of Physical Activity on Spirometry and Fractional Exhaled Nitric Oxide in Adolescents-Longitudinal Study
}

\author{
Kamil Barański $^{1}{ }^{\mathbb{D}}$, Krzysztof Kocot ${ }^{1, * \mathbb{D}}$, Edyta Melaniuk-Wolny ${ }^{2} \mathbb{D}$, Elwira Zajusz-Zubek ${ }^{2} \mathbb{D}$ and \\ Małgorzata Kowalska ${ }^{1}$ (D)
}

1 Department of Epidemiology, Faculty of Medical Sciences in Katowice, Medical University of Silesia in Katowice, 40-752 Katowice, Poland; kbaranski@sum.edu.pl (K.B.); mkowalska@sum.edu.pl (M.K.)

2 Department of Air Protection, Faculty of Energy and Environmental Engineering, Silesian University of Technology in Gliwice, 44-100 Gliwice, Poland; edyta.melaniuk-wolny@polsl.pl (E.M.-W.);

elwira.zajusz-zubek@polsl.pl (E.Z.-Z.)

* Correspondence: d200800@365.sum.edu.pl or kjkocot@gmail.com

check for

updates

Citation: Barański, K.; Kocot, K.; Melaniuk-Wolny, E.; Zajusz-Zubek, E.; Kowalska, M. The Effect of Physical Activity on Spirometry and Fractional Exhaled Nitric Oxide in Adolescents-Longitudinal Study. Sustainability 2021, 13, 5770 . https://doi.org/10.3390/su13115770

Academic Editors: Josep Vidal-Conti, Pere Palou and Adrià Muntaner-Mas

Received: 20 April 2021

Accepted: 17 May 2021

Published: 21 May 2021

Publisher's Note: MDPI stays neutral with regard to jurisdictional claims in published maps and institutional affiliations.

Copyright: (c) 2021 by the authors. Licensee MDPI, Basel, Switzerland. This article is an open access article distributed under the terms and conditions of the Creative Commons Attribution (CC BY) license (https:// creativecommons.org/licenses/by/ $4.0 /)$.

\begin{abstract}
Highly intense and chronic physical activity may cause an inflammatory process in the airways. The inflammatory process in the respiratory system can be measured either by the spirometry test and exhaled nitric oxide. The aim of this study was to assess the effect of different levels of physical activity on fractional exhaled nitric oxide (FeNO) and spirometry parameters. Fifty healthy students (volunteers) who were participating in physical activity classes (low level of physical activity) and attending sports training (high and medium level of physical activity) completed two indoor exercise training two to three weeks apart. FeNO was measured twice, at baseline and after 45-60 min of exercise followed by spirometry. There was no significant difference in FeNO values and spirometry parameters between the groups with different physical activity. However, students with the highest level of physical activity presented a higher and significant variance of FeNO levels in comparison to students with lower physical activity. Healthy young adults (professional sportspersons) have a higher internal variability of FeNO. That suggests the initial ongoing inflammatory process in the airways. Any level of physical activity does not affect spirometry parameters before and after training in young healthy adults.
\end{abstract}

Keywords: exercise; spirometry; nitric oxide; young adult; inflammation

\section{Introduction}

Systematic physical activity plays a key role in well-being and brings a lot of health benefits. On the other hand, it may bring negative effects as well [1,2]. Moreover, highintensity exercises may provoke an inflammatory process and cause acute respiratory symptoms. Additionally, chronic and high-intensity exercises may provide bronchoconstriction and exercise-induced asthma issues [3]. Nitric oxide (NO) is produced in animals by three different forms of enzyme-nitric oxide synthase: neuronal (nNOS), endothelial (eNOS), and induced (iNOS) [4]. Exercise also stimulates nitric oxide (NO) release from endothelial cells [5]. Several cell types can produce nitric oxide in the airway mucosa [6]. The amount of NO released from the airway mucosa can be affected by disease factors (atopy, respiratory infections) and non-disease factors (coffee intake, tobacco exposure, physical activity), as well as anthropometric factors (age, height, ethnicity) [6,7].

Fractional exhaled nitric oxide (FeNO) is an important marker of eosinophilic airways inflammation [8]. The variability of FeNO in healthy humans is well studied but in small groups of participants $[9,10]$. The effect of physical activity has been investigated before and results suggest that vigorous physical activity correlates with higher FeNO values in less active healthy adolescents. The same results have been confirmed in children [10]. On the other hand, there is strong evidence that very vigorous physical activity has a very strong effect on increased FeNO values [11]. 
Studies performed in healthy young adults are important for determining the physiological response to exercise, unbiased by factors such as chronic diseases. This may further be helpful to assess how different levels of physical exercise may affect health University students who have regular scheduled trainings are a particularly attractive group for the assessment of physiological responses to exercise. The above-mentioned arguments motivated us to build the following hypothesis in a group of students who have regular and controlled physical activity due to their schedule:

Hypothesis 1: Students who have a higher level of physical activity have higher FeNO values after training in comparison to students who have lower physical activity per day.

Hypothesis 2: Students with different physical activity differ in spirometry parameters and FeNO levels between the groups and within the groups.

\section{Materials and Methods}

\subsection{Study Design}

The prospective cohort study was performed between October 2019 and March 2020. The participants were students of the Silesian University of Technology located in Gliwice. Over 120 students were randomly selected to participate in the study. After considering inclusion criteria (e.g., no chronic respiratory diseases, allergies, and chronic cardiovascular disease, willing to participate, no smoker, age between 18 and 30), and cleaning the dataset, there were 50 participants in whom, overall, there were 200 tests performed. Students were divided into the different groups of physical activity according to their declaration in the questionnaire ( 1 analysis: 1 day per week $=$ low, 2-3 days per week $=$ middle, more than 3 days per week = high; 2 analysis: less than $2 \mathrm{~h}$ a day $=$ low activity and 2 or more hours a day = high activity) and according to the sports section in which they were assigned. The high and middle activity students were mostly students who were members of the University Sports Association (Akademicki Zwiazek Sportowy-AZS). The highly active groups were basketball players and judo fighters. Middle activity students were mostly football players and volleyball players. The lowest activity was reserved for students exercising only during obligatory physical education classes and who did not assign themselves to any sports sections at the university. The type and intensity of physical activity was not affected by the authors. The sports activities included mainly volleyball, basketball and judo.

Anthropometric data such as weight and body mass were measured before the training. FeNO (Vivatmo pro, Bosch Healthcare Solutions $\mathrm{GmbH}$, Waibilingen, Germany) and spirometric (Easy One Air, NDD Medizintechnik AG, Zurich, Switzerland) measurements were performed before the training and briefly after $60 \mathrm{~min}$ of physical activity. Each student was measured by a qualified technician. FeNO was measured prior to spirometry.

FeNO was measured 3 times for each session of measurement and expressed as the mean (before training and after the training). The reliability of Bosch Vivatmo Pro has been investigated elsewhere. The results confirmed its utility for clinical practice [12]. The measurements kept the ATS/ERS guidelines recommendations for obtaining valid results [13].

Spirometric tests were performed until the satisfying result of the quality of measurement was obtained. Quality grade equals $C$ defined as 2 acceptable maneuverers and the maximum difference between measurement of FVC $0.2(\mathrm{~L})$. The measurements were performed according to ATS/ERS guidelines [14].

In summary, all 50 participants were tested four times: once before training, secondly briefly after the training and the procedure were repeated two or three weeks apart.

All subjects gave their informed consent for inclusion before they participated in the study. The study was conducted in accordance with the Declaration of Helsinki, and the protocol was approved by the Ethics Committee of the Medical University of Silesia in Katowice (agreement no. PCN/0022/KB1/125/I/19). 


\subsection{Statistical Analysis}

The quantitative variables were expressed as the mean and standard deviation. The qualitative variables were expressed as frequency $(\mathrm{n})$ and percentage (\%). The relationship between qualitative variables was assessed by the Chi-square test or Fisher test, as appropriate. The Shapiro-Wilk test was used to assess the normal distribution for quantitative variables. Comparisons between low activity ( $<2 \mathrm{~h}$ of physical activity per day) vs. high activitye ( $\geq 2 \mathrm{~h}$ of physical activity per day) were made with the paired parametric or non-parametric test, used as appropriate (paired t-test or Wilcoxon test). The parametric ANOVA or non-parametric Kruskal-Wallis test was used as appropriate for the comparison of the 3 groups (low vs. middle vs. high activity) of physical activity. The influence of variables on FeNO or spirometric results was investigated with general linear models for repeated measurements. Such analysis was well performed for the selection of the confounding variables and multicollinearity. The sphericity was tested with the Muchly test. Since the data violated the assumption of sphericity, the Greenhouse-Geisser test was used for further interpretation of the results. Bonferroni correction was used in post hoc analysis. Variables included in the models were: age, BMI, sex, and physical activity level (low vs. medium vs. high) in the first model or physical activity level (low ' $<2 \mathrm{~h}$ per day' or high ' $\geq 2 \mathrm{~h}$ per day') in the second model. The level of significance in statistical analysis was set at $p<0.05$ value. All analyses were performed with TIBCO Software Inc. (2017) Palo Alto, USA. Statistica (data analysis software system), version 13 and SAS 9.4 (SAS Institute Inc., Cary, NC, USA) software.

\section{Results}

\subsection{The Characteristics of the Study Group}

Fifty participants were included in the final analysis. The age of participants ranged between $18-29$ years old and the mean was $20.3 \pm 2.3$ years. A total of $54 \%(n=27)$ were female and $46 \%(\mathrm{n}=23)$ were male. The mean age of males was $19.6 \pm 1.2$ and for females was $20.9 \pm 2.8$ and did not significantly differ $(\mathrm{p}=0.05)$. The mean height was $1.7 \pm 0.1 \mathrm{~m}$, body mass $73.0 \pm 15.3 \mathrm{~kg}$, and BMI $23.5 \pm 4.2 \mathrm{~kg} / \mathrm{m} 2$. Most of the participants, $70 \%(\mathrm{n}=35)$, were living in a big city ( $>100,000$ inhabitants). Students were asked to assess their physical condition (physical performance). A total of $56 \%(n=28)$ described their condition as good. Moreover, they were asked if they worked out outside. Only $22 \%(n=11)$ declared that they do sports outside but apart from the winter season. Participants also answered the question of whether they avoided training outside during smog episodes. Most of them, $72 \%(n=36)$, declared that "sometimes" they care about avoiding smog episodes while doing sports. The description of study groups regarding the different levels of physical activity is presented in Tables 1-4.

Table 1. Anthropometric variables, physical activity, spirometry results, and FeNO values in study participants according to different levels of physical activity $(n=50)$.

\begin{tabular}{ccccc}
\hline \multirow{2}{*}{ Variable } & \multicolumn{3}{c}{ Physical Activity } & \multirow{2}{*}{ P Value } \\
\cline { 2 - 4 } & $\begin{array}{c}\text { Low } \\
\mathbf{n}=\mathbf{2 4}\end{array}$ & $\begin{array}{c}\text { Middle } \\
\mathbf{n}=\mathbf{1 3}\end{array}$ & $\begin{array}{c}\text { High } \\
\mathbf{n}=\mathbf{1 3}\end{array}$ \\
\hline Quantitative Variables \\
\hline Age (years) & $19.5 \pm 0.7$ & $19.6 \pm 0.5$ & $22.5 \pm 3.7$ & 0.006 \\
\hline Sex (n;\%) Female & $9 ; 33.3 \%$ & $8 ; 29.7 \%$ & $10 ; 37.0 \%$ & 0.05 \\
\hline Body mass $(\mathrm{kg})$ & $73.8 \pm 17.7$ & $69.2 \pm 13.0$ & $75.3 \pm 13.1$ & 0.5 \\
\hline Height $(\mathrm{m})$ & $1.7 \pm 0.1$ & $1.7 \pm 0.1$ & $1.8 \pm 0.1$ & 0.004 \\
\hline BMI $\left(\mathrm{kg} / \mathrm{m}^{2}\right)$ & $24.4 \pm 5.2$ & $23.1 \pm 3.0$ & $22.4 \pm 2.5$ & 0.6 \\
\hline
\end{tabular}


Table 1. Cont.

\begin{tabular}{|c|c|c|c|c|}
\hline \multirow[b]{2}{*}{ Variable } & \multicolumn{3}{|c|}{ Physical Activity } & \multirow[b]{2}{*}{ P Value } \\
\hline & $\begin{array}{l}\text { Low } \\
\mathrm{n}=24\end{array}$ & $\begin{array}{l}\text { Middle } \\
\mathrm{n}=13\end{array}$ & $\begin{array}{l}\text { High } \\
\mathrm{n}=13\end{array}$ & \\
\hline & \multicolumn{4}{|c|}{ Qualitative variables } \\
\hline $\begin{array}{l}\text { Place of residence } \\
\text { City vs. village }\end{array}$ & $14 ; 40 \%$ & $8 ; 22.8 \%$ & $13 ; 37.2 \%$ & 0.02 \\
\hline $\begin{array}{l}\text { Self-perceived condition (n;\%) } \\
\text { Good vs. bad }\end{array}$ & $10 ; 35.7 \%$ & $6 ; 21.4 \%$ & $12 ; 42.8 \%$ & 0.008 \\
\hline $\begin{array}{l}\text { Outdoor exercise (n;\%) } \\
\text { except winter season vs. no }\end{array}$ & $3 ; 27.2 \%$ & $2 ; 18.2 \%$ & $6 ; 54.5 \%$ & 0.04 \\
\hline $\begin{array}{l}\text { Avoiding exercise during smog episodes } \\
\qquad(\mathrm{n} ; \%) \\
\text { Yes vs. no }\end{array}$ & $3 ; 21.4 \%$ & $7 ; 50.0 \%$ & $4 ; 28.6 \%$ & 0.02 \\
\hline
\end{tabular}

Table 2. Respiratory results and FeNO values in study participants according to different levels of physical activity $(n=50)$.

\begin{tabular}{|c|c|c|c|c|c|}
\hline \multirow{2}{*}{\multicolumn{2}{|c|}{ Variable }} & \multicolumn{3}{|c|}{ Physical Activity } & \multirow[b]{2}{*}{ P Value } \\
\hline & & $\begin{array}{c}\text { Low } \\
n=24\end{array}$ & $\begin{array}{c}\text { Middle } \\
\mathrm{n}=13\end{array}$ & $\begin{array}{c}\text { High } \\
n=13\end{array}$ & \\
\hline \multirow{4}{*}{ FeNO (ppb) } & 1PreT & $13.5 \pm 4.3$ & $12.3 \pm 5.1$ & $12.4 \pm 5.3$ & 0.7 \\
\hline & 1PostT & $12.5 \pm 4.7$ & $12.8 \pm 4.9$ & $13.0 \pm 6.1$ & 0.9 \\
\hline & 2 PreT & $13.1 \pm 4.8$ & $12.2 \pm 4.7$ & $18.1 \pm 5.4$ & 0.005 \\
\hline & 2Post T & $13.6 \pm 4.7$ & $13.1 \pm 3.8$ & $16.0 \pm 4.8$ & 0.2 \\
\hline \multirow{4}{*}{ FVC (l) } & 1PreT & $4.69 \pm 1.0$ & $4.59 \pm 0.6$ & $4.94 \pm 0.9$ & 0.6 \\
\hline & 1PostT & $4.69 \pm 1.0$ & $4.54 \pm 0.6$ & $4.84 \pm 0.9$ & 0.7 \\
\hline & 2 PreT & $4.68 \pm 1.0$ & $4.70 \pm 0.6$ & $4.88 \pm 0.9$ & 0.8 \\
\hline & 2PostT & $4.71 \pm 1.0$ & $4.63 \pm 0.7$ & $4.87 \pm 1.0$ & 0.8 \\
\hline \multirow{4}{*}{ FEV1 (l) } & 1PreT & $4.02 \pm 0.7$ & $4.00 \pm 0.5$ & $3.98 \pm 0.6$ & 0.9 \\
\hline & 1PostT & $4.04 \pm 0.7$ & $4.03 \pm 0.5$ & $3.95 \pm 0.6$ & 0.9 \\
\hline & 2 PreT & $4.06 \pm 0.7$ & $4.15 \pm 0.5$ & $3.96 \pm 0.6$ & 0.7 \\
\hline & 2PostT & $4.08 \pm 0.7$ & $4.10 \pm 0.5$ & $3.98 \pm 0.6$ & 0.8 \\
\hline \multirow{4}{*}{ FEF25 (l) } & 1PreT & $7.41 \pm 1.3$ & $7.45 \pm 1.8$ & $6.81 \pm 0.9$ & 0.4 \\
\hline & 1PostT & $7.31 \pm 1.2$ & $7.47 \pm 1.8$ & $6.68 \pm 0.9$ & 0.2 \\
\hline & 2 PreT & $7.36 \pm 1.4$ & $7.63 \pm 1.8$ & $6.52 \pm 1.0$ & 0.1 \\
\hline & 2PostT & $7.52 \pm 1.3$ & $7.41 \pm 1.5$ & $6.54 \pm 0.8$ & 0.08 \\
\hline \multirow{4}{*}{ FEF50 (l) } & 1PreT & $4.95 \pm 0.7$ & $5.54 \pm 1.0$ & $4.51 \pm 1.1$ & 0.03 \\
\hline & 1PostT & $5.02 \pm 0.8$ & $5.57 \pm 1.1$ & $4.54 \pm 1.1$ & 0.04 \\
\hline & 2 PreT & $5.21 \pm 0.8$ & $5.80 \pm 1.0$ & $4.58 \pm 1.28$ & 0.01 \\
\hline & 2 Post T & $5.02 \pm 0.6$ & $5.74 \pm 1.0$ & $4.57 \pm 1.1$ & 0.009 \\
\hline \multirow{4}{*}{ FEF75 (l) } & 1PreT & $2.43 \pm 0.5$ & $2.59 \pm 0.7$ & $2.06 \pm 2.1$ & 0.1 \\
\hline & 1Post T & $2.47 \pm 0.5$ & $2.80 \pm 0.8$ & $2.13 \pm 0.7$ & 0.04 \\
\hline & 2 PreT & $2.62 \pm 0.4$ & $2.60 \pm 0.6$ & $2.06 \pm 0.6$ & 0.02 \\
\hline & 2PostT & $2.48 \pm 0.5$ & $2.69 \pm 0.7$ & $2.17 \pm 0.7$ & 0.1 \\
\hline
\end{tabular}

Legend: 1PreT-measurement before training (1st session), 1PostT-measurement after $1 \mathrm{~h}$ of training (1st session), 2PreT-measurement before training (2nd session), 2PostT-measurement after $1 \mathrm{~h}$ of training (2nd session). 
Table 3. Anthropometric variables, physical activity, spirometry results, and FeNO values in study participants according to different daily physical activity $(n=50)$.

\begin{tabular}{|c|c|c|c|}
\hline \multirow[b]{2}{*}{ Variable } & \multicolumn{2}{|c|}{ Physical Activity } & \multirow[b]{2}{*}{ P Value } \\
\hline & $\begin{array}{c}\text { Low }(<2 \mathrm{~h}) \\
\mathrm{n}=38\end{array}$ & $\begin{array}{l}\text { High }(\geq 2 h) \\
\quad n=12\end{array}$ & \\
\hline & \multicolumn{3}{|c|}{ Quantitative Variables } \\
\hline Age (years) & $19.7 \pm 0.9$ & $22.2 \pm 4.0$ & 0.05 \\
\hline Sex $(n ; \%)$ Female & $16 ; 59.3 \%$ & $11 ; 40.7 \%$ & 0.002 \\
\hline Body mass & $72.0 \pm 16.0$ & $76.0 \pm 13.1$ & 0.2 \\
\hline Height & $1.7 \pm 0.1$ & $1.8 \pm 0.1$ & 0.02 \\
\hline \multirow[t]{2}{*}{ BMI } & $23.7 \pm 4.6$ & $23.0 \pm 2.5$ & 0.9 \\
\hline & \multicolumn{3}{|c|}{ Qualitative Variables } \\
\hline $\begin{array}{l}\text { Place of residence } \\
\text { City }\end{array}$ & $25 ; 71.4 \%$ & $10 ; 28.5 \%$ & 0.2 \\
\hline $\begin{array}{l}\text { Self-perceived condition (n;\%) } \\
\text { Good }\end{array}$ & $18 ; 64,3 \%$ & $10 ; 35.7 \%$ & 0.02 \\
\hline $\begin{array}{l}\text { Outdoor exercise }(\mathrm{n} ; \%) \\
\text { Not at all }\end{array}$ & $32 ; 82 \%$ & $7 ; 18 \%$ & 0.05 \\
\hline $\begin{array}{l}\text { Avoiding exercise during smog episodes }(\mathrm{n} ; \%) \\
\text { Yes }\end{array}$ & $9 ; 64.3 \%$ & $5 ; 35.7 \%$ & 0.2 \\
\hline
\end{tabular}

Table 4. Respiratory results and FeNO values in study participants according to different levels of physical activity $(n=50)$.

\begin{tabular}{|c|c|c|c|c|}
\hline \multirow{2}{*}{\multicolumn{2}{|c|}{ Variable }} & \multicolumn{2}{|c|}{ Physical Activity } & \multirow[b]{2}{*}{ P Value } \\
\hline & & $\begin{array}{c}\text { Low }(<2 \mathrm{~h}) \\
\mathrm{n}=38\end{array}$ & $\begin{array}{l}\text { High }(\geq 2 \mathrm{~h}) \\
\quad \mathrm{n}=12\end{array}$ & \\
\hline \multirow{4}{*}{ FeNO (ppb) } & 1PreT & $13.9 \pm 4.5$ & $9.8 \pm 4.1$ & 0.009 \\
\hline & 1PostT & $13.4 \pm 4.7$ & $10.3 \pm 5.5$ & 0.05 \\
\hline & $2 \mathrm{PreT}$ & $13.2 \pm 4.9$ & $17.29 \pm 5.8$ & 0.04 \\
\hline & 2PostT & $13.8 \pm 4.6$ & $15.13 \pm 4.5$ & 0.2 \\
\hline \multirow{4}{*}{ FVC (1) } & 1PreT & $4.69 \pm 0.9$ & $4.83 \pm 0.9$ & 0.7 \\
\hline & 1 PostT & $4.69 \pm 0.9$ & $4.69 \pm 0.9$ & 0.7 \\
\hline & 2 PreT & $4.72 \pm 0.9$ & $4.79 \pm 1$ & 0.9 \\
\hline & 2PostT & $4.73 \pm 0.9$ & $4.73 \pm 0.9$ & 0.9 \\
\hline \multirow{4}{*}{ FEV1 (l) } & 1PreT & $4.03 \pm 0.6$ & $3.95 \pm 0.6$ & 0.7 \\
\hline & 1 PostT & $4.05 \pm 0.6$ & $3.89 \pm 0.6$ & 0.4 \\
\hline & 2 PreT & $4.09 \pm 0.6$ & $3.94 \pm 0.6$ & 0.4 \\
\hline & 2PostT & $4.10 \pm 0.6$ & $3.93 \pm 0.6$ & 0.4 \\
\hline \multirow{4}{*}{ FEF25 (l) } & 1PreT & $7.41 \pm 1.50$ & $6.79 \pm 0.9$ & 0.1 \\
\hline & 1PostT & $7.37 \pm 1.45$ & $6.64 \pm 0.9$ & 0.1 \\
\hline & 2 PreT & $7.40 \pm 1.55$ & $6.61 \pm 1.1$ & 0.1 \\
\hline & 2PostT & $7.46 \pm 1.38$ & $6.54 \pm 0.8$ & 0.03 \\
\hline \multirow{4}{*}{ FEF50 (l) } & 1 PreT & $5.11 \pm 0.9$ & $4.61 \pm 1.0$ & 0.1 \\
\hline & 1PostT & $5.16 \pm 1.0$ & $4.66 \pm 1.1$ & 0.1 \\
\hline & 2 PreT & $5.35 \pm 1.0$ & $4.74 \pm 1.2$ & 0.08 \\
\hline & 2 PostT & $5.21 \pm 0.9$ & $4.72 \pm 1.1$ & 0.1 \\
\hline \multirow{4}{*}{ FEF75 (l) } & 1 PreT & $2.43 \pm 0.6$ & $2.18 \pm 0.8$ & 0.2 \\
\hline & 1PostT & $2.54 \pm 0.6$ & $2.21 \pm 0.8$ & 0.1 \\
\hline & 2 PreT & $2.55 \pm 0.5$ & $2.21 \pm 0.8$ & 0.09 \\
\hline & 2PostT & $2.51 \pm 0.6$ & $2.28 \pm 0.7$ & 0.3 \\
\hline
\end{tabular}

Legend: 1PreT-measurement before training (1st session), 1PostT-measurement after $1 \mathrm{~h}$ of training (1st session), 2PreT-measurement before training (2nd session), 2PostT-measurement after $1 \mathrm{~h}$ of training (2nd session). 
3.2. Analysis of FeNO and Spirometry Results by Different Levels of Physical Activity (Low vs. Medium vs. High)

A repeated-measures ANOVA with a Greenhouse-Geisser correction determined that the mean FeNO level differed significantly between time points but only for students who kept high physical activity $\left(F(6,141)=3.01, \mathrm{p}<0.01, \eta \mathrm{p}^{2}=0.11\right)$. Post hoc tests using the Bonferroni correction revealed that students with high physical activity before the second training had significantly higher FeNO values in comparison to the first pre-training measurements and first post-training measurement $(18.1 \pm 5.4 \mathrm{ppb}$ vs. $13.0 \pm 6.1 \mathrm{ppb}$ vs. $12.4 \pm 5.3 \mathrm{ppb}$, respectively, $\mathrm{p}=0.01$ and $\mathrm{p}=0.002$, respectively). There were no significant between-group differences (Figure 1). Moreover, the results did not change after controlling for BMI, age, and sex. After conducting two-way repeated measures ANOVA, the results showed no significant differences. $F(3,44)=1.53, p=0.2$ between measurements, $\mathrm{F}(6,88)=1.04, \mathrm{p}=0.4$ for interaction between FeNO levels and weekly level of physical activity, and there was no interaction between FeNO levels and groups of students who were professional sportspersons vs. non sportspersons $(F(3,44)=0.65, p=0.5$.

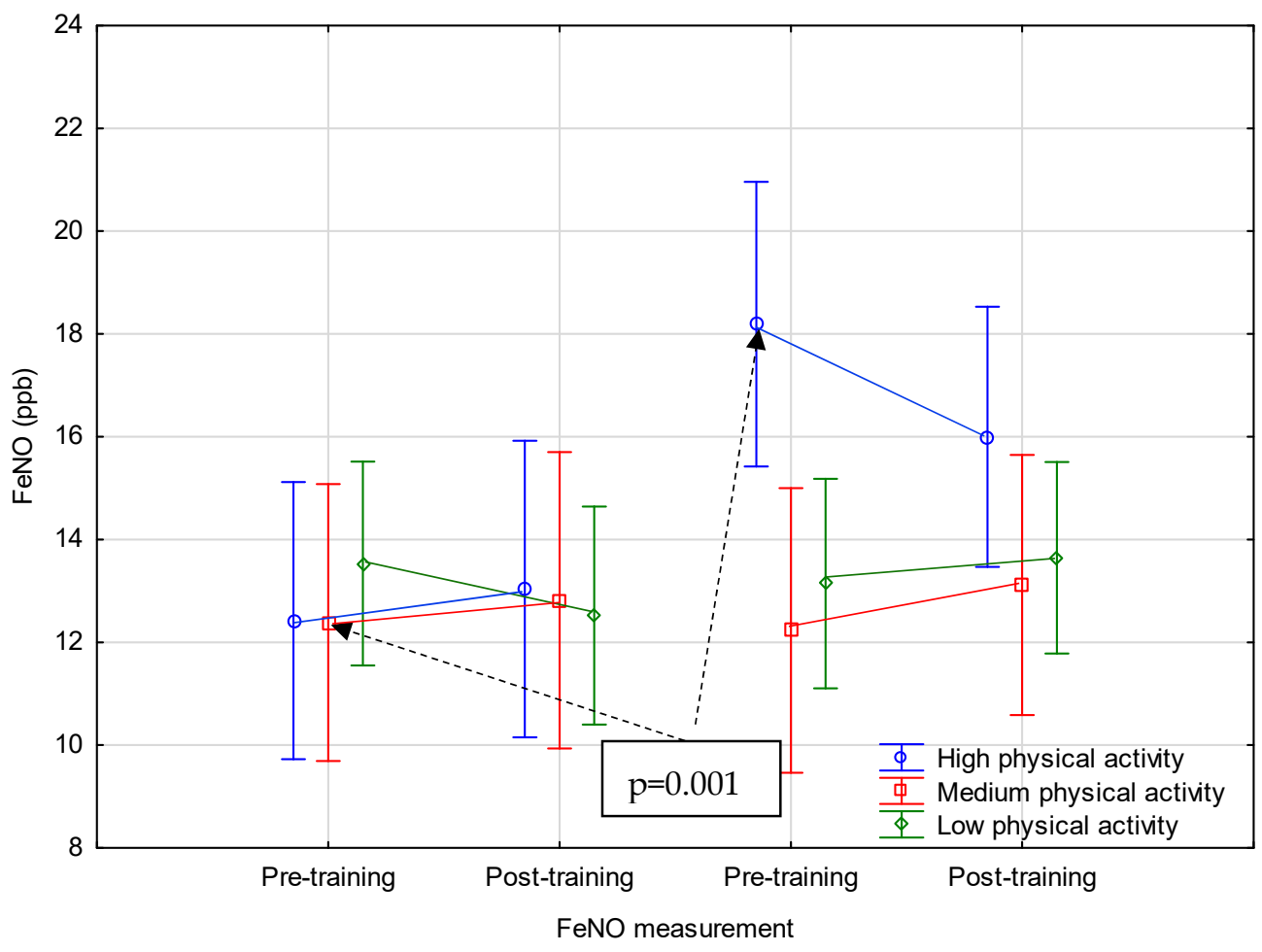

Figure 1. FeNO values during the first and second session of training according to physical activity groups (high vs. medium vs. low).

The same analyses were performed for spirometry variables. There were no effects between groups of physical activity except variable sex.

3.3. Analysis of FeNO and Spirometry Results by Daily Physical Activity $(<2 h$ per Day vs. $\geq 2 h$ per Day)

In the analysis which focused on the effect of daily physical activity, an effect was found only in groups of students who performed $\geq 2 \mathrm{~h}$ of physical activity daily, and there was the interaction of physical activity with time between measurements. Significant differences were found between FeNO values $17.2 \pm 5.8$ ppb vs. $9.8 \pm 4.1 \mathrm{ppb} p=0.001$; $15.1 \pm 4.5 \mathrm{ppb}$ vs. $9.8 \pm 4.1 \mathrm{ppb} \mathrm{p}=0.03 ; 17.2 \pm 5.8 \mathrm{ppb}$ vs. $10.3 \pm 5.5 \mathrm{ppb} \mathrm{p}=0.001$ and 15.1 $\pm 4.5 \mathrm{ppb}$ vs. $10.3 \pm 5.5 \mathrm{ppb} \mathrm{p}=0.01$ (Figure 2). There were no significant between-group differences. Moreover, the results did not change after controlling for BMI, age, and sex. 
The same analyses were performed for spirometry variables. There was no effects between groups of physical activity except variable sex.

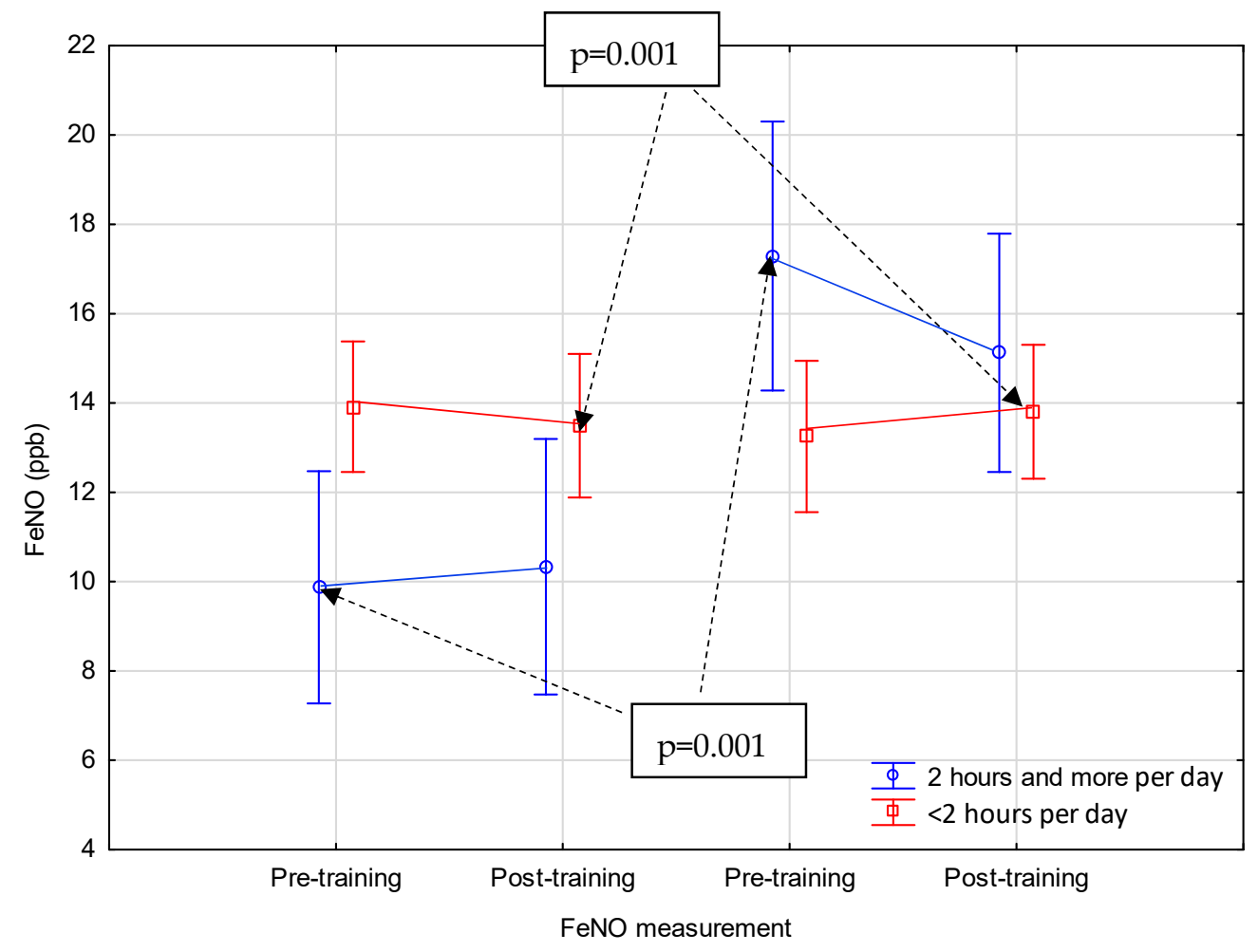

Figure 2. FeNO values during the first and second session of training according to daily time during physical activity ( $\geq 2 \mathrm{~h}$ per day vs. $<2 \mathrm{~h}$ per day).

After conducting two-way repeated measures ANOVA, the results showed no significant differences. $F(3,44)=1.77, p=0.1$ between measurements, $F(3,44)=2.43, p=0.07$ for interaction between FeNO levels and daily level of physical activity, and there was no interaction between FeNO levels and groups of students who were professional sportspersons vs. non sportspersons and daily physical activity $(F(3,44)=1.06, p=0.3$.

\section{Discussion}

The current knowledge regarding the diurnal FeNO variability shows its minimal variation. In five subsequent days, the FeNO coefficient of variation (CV) in the morning was $15.4 \%$ and $13.6 \%$ in the evening in the healthy subjects located at $2240 \mathrm{~m}$ above the sea [15]. Other researchers suggest slight FeNO variation with the highest values in the morning and the lowest values in the evening [16]. However, there are contradictory findings of the daily variability of FeNO in healthy subjects. Stark et al. suggest that because of diurnal FeNO variation, it is more reasonable to perform measurements at the same time of the day, especially while conducting a long-term follow-up study [9]. The results of our study confirm consistent and low variability between occasional measurements of FeNO at the same time of the day [17].

FeNO is a well-established marker of eosinophilic airways inflammation (Dweik, Hoyte) [17]. The measurement of FeNO may be useful in the diagnosis and control of asthma [18]. Moreover, elevated FeNO values may be used as a predictor of exerciseinduced bronchoconstriction, even in non-asthmatics $[19,20]$. According to the available bibliography, short-term physical exercise usually leads to acute FeNO decreasing [6,21]. Less is known about the effects of longer-lasting and regular physical activity on FeNO values. Prosseger et al. reported a decrease in FeNO after ten days of recreational winter sports in healthy adults [22]. In contrast, some findings suggest that very vigorous physical activity in contrast to total daily physical activity is associated with increased FeNO in 
non-asthmatic adolescents. That also suggests that intense physical activity may induce an inflammatory process in airways independently of asthma [23]. Our study slightly confirms the results of the study conducted by Sachs-Olsen et al. because the FeNO values were non-statistically higher in very active students. However, we found that the young healthy adults with vigorous physical activity have a non-stable variability of FeNO. It is probably because of the type of sport trained by students, but it might be caused by the winter season and smog episodes. We recorded the air pollutants concentrations during the measurements and a couple of days before the measurements (lag effect) and we found no statistically significant correlations with the respiratory parameters, which is contradictory to the results presented in our last study [24]. Berhane's team confirmed the role of air pollution, but they conducted a cohort study in children [25].

The available literature suggests that healthy people who do sports have higher spirometric volumes [26,27], while our results showed that spirometry parameters do not differ before and after the training. Additionally, there were no significant results after the next follow-up. These findings confirm the results of the study conducted by Smith [28]. In our study, we did not consider the type of sport which may play an important role in determining respiratory parameters. It seems that rowers, basketball, and water polo athletes improve their respiratory parameters [29]. A better understanding of such findings might be crucial in determining the size and direction of the physical activity effect on respiratory functions.

It is important to note that our results confirm that FeNO levels depend on individual factors because of the internal variability of $\mathrm{FeNO}$ in high-intensity exercise students. Moreover, having the FeNO values below the upper limits may be a sign of normal respiratory function, because of sustainable development. In a whole group of healthy students, the FeNO values did not cross $50 \mathrm{ppb}$ and they were close to the intermediate results (30 ppb) [30].

Our study has several limitations. Firstly, we only analysed 50 participants $(42 \%$ participation rate) from 120 participants. This was due to several reasons. Among others include, a lack of measurements, their low quality (because of the participants' execution) and inclusion criteria. Furthermore, the physical training was not performed on the same dates. Moreover, there is a chance that some training was more intense. The training was not standardized; however, it could be difficult to solve since professional athletes have training plans. Another limitation was that we have not analyzed reference and predictive spirometry variables. However, the raw results did not significantly differ between the groups, which gave us a reason to not continue the analysis and leave it for future research. Despite the high number of participants and number of measurements, which is a good aspect of this study, the power of the study is not satisfying.

The last limitation of our study was that we did not assess other inflammatory biomarkers, which could increase the strength of the study.

The strength of the study is that we followed one person with four measurements, which allowed us to assess the respiratory functions more accurately. All measurements were taken outside the clinic by qualified professionals.

\section{Conclusions}

People with a higher level of physical activity have slightly higher FeNO values in comparison to less active people. Moreover, healthy young adults who do sports professionally have higher FeNO variability. Physical activity should not affect spirometry parameters before and after training in young healthy adults.

Author Contributions: Conceptualization, K.B., K.K.; methodology, K.B., K.K., M.K.; software, K.B.; validation, M.K., E.M.-W.; formal analysis, K.B.; investigation, K.B., K.K., E.M.-W., M.K.; resources, M.K., E.M.-W.; data curation, K.B., K.K.; writing-original draft preparation, K.B., M.K., K.K.; writing-review and editing, K.B., K.K., M.K., E.Z.-Z.; visualization, K.B.; supervision, M.K.; project administration, M.K., E.M.-W., E.Z.-Z.; funding acquisition, M.K., E.Z.-Z. All authors have read and agreed to the published version of the manuscript. 
Funding: This research was funded by Medical University of Silesia in Katowice, internal grant KNW-1-154/K/9/0 and PCN-1-016/K/0/I.

Institutional Review Board Statement: The study was conducted according to the guidelines of the Declaration of Helsinki, and approved by the Ethics Committee of Medical University of Silesia in Katowice (agreement number PCN/0022/KB1/125/I/19 from 3rd December 2019).

Informed Consent Statement: Informed consent was obtained from all subjects involved in the study.

Data Availability Statement: The data are available on request from the Department of Epidemiology, Medical University of Silesia in Katowice. The request should be formulated and sent to epikat@sum.edu.pl.

Acknowledgments: The authors would like to thank all students of Silesian University of Technology in Gliwice who took part in the study.

Conflicts of Interest: The authors declare no conflict of interest.

\section{References}

1. Malm, C.; Jakobsson, J.; Isakkson, I. Physical Activity and Sports-Real Health Benefits: A Review with Insight into the Public Health of Sweden. Sports 2019, 7, 127. [CrossRef]

2. Araneda, O.F.; Carbonell, T.; Tuesta, M. Update on the Mechanisms of Pulmonary Inflammation and Oxidative Imbalance Induced by Exercise. Oxid. Med. Cell. Longev. 2016, 2016, 4868536. [CrossRef]

3. Cerqueira, É.; Marinho, D.A.; Neiva, H.P.; Lourenço, O. Inflammatory Effects of High and Moderate Intensity Exercise-A Systematic Review. Front. Physiol. 2020, 10, 1550. [CrossRef]

4. Sokołowska, M.; Włodek, L. Good and bad sides of nitric oxide. Folia Cardiol. Excerpta 2001, 8, 467-474.

5. Moncada, S. Nitric oxide in the vasculature: Physiolgy and pathophysiology. Ann. N. Y. Acad. Sci. 1977, 811, 60-67. [CrossRef] [PubMed]

6. Evjenth, B.; Hansen, T.E.; Holt, J. Exhaled nitric oxide decreases during exercise in non-asthmatic children. Clin. Respir. J. 2013, 7, 121-127. [CrossRef]

7. Zejda, J.E.; Barański, K.; Brożek, G. Anthropometric and Spirometric Correlates of FeNO in Healthy Schoolchildren. J. Investig. Allergol. Clin. Immunol. 2016, 26, 137-138. [CrossRef]

8. Hoyte, F.C.L.; Gross, L.M.; Katial, R.K. Exhaled Nitric Oxide: An Update. Immunol. Allergy Clin. North Am. 2018, 38, 573-585. [CrossRef]

9. Stark, H.; Purokivi, M.; Kiviranta, J.; Tukiainen, H. Short-term and seasonal variations of exhaled and nasal NO in healthy subjects. Respir. Med. 2007, 101, 265-271. [CrossRef] [PubMed]

10. Ekroos, H.; Karjalainen, J.; Sarna, S.; Laitinen, L.A.; Sovijärvi, A.R.A. Short-term variability of exhaled nitric oxide in young male patients with mild asthma and in healthy subjects. Respir. Med. 2002, 96, 895-900. [CrossRef]

11. Lovinsky-Desir, S.; Jung, K.H.; Rundle, A.G.; Hoepner, L.A.; Bautista, J.B.; Perera, F.; Chillrud, S.N.; Perzanowski, M.S.; Miller, R.L. Physical activity, black carbon exposure and airway inflammation in an urban adolescent cohort. Environ. Res. 2016, 151, 756-762. [CrossRef] [PubMed]

12. Korn, S.; Wilk, M.; Voigt, S.; Weber, S.; Keller, T.; Buhl, R. Measurement of Fractional Exhaled Nitric Oxide: Comparison of Three Different Analysers. Respiration 2020, 99, 1-8. [CrossRef] [PubMed]

13. American Thoracic Society; European Respiratory Society. ATS/ERS recommendations for standardized procedures for the online and offline measurement of exhaled lower respiratory nitric oxide and nasal nitric oxide, 2005. Am. J. Respir. Crit. Care Med. 2005, 171, 912-930. [CrossRef]

14. Graham, B.L.; Steenbruggen, I.; Miller, M.R.; Barjaktarevic, I.Z.; Cooper, B.G.; Hall, G.L.; Hallstrand, T.S.; Kaminsky, D.A.; McCarthy, K.; McCormack, M.C.; et al. Standardization of Spirometry 2019 Update. An Official American Thoracic Society and European Respiratory Society Technical Statement. Am. J. Respir. Crit. Care Med. 2019, 200, e70-e88. [CrossRef]

15. Gochicoa-Rangel, L.; Rojas-Cisneros, F.; Miguel-Reyes, J.L.; Guerrero-Zúñiga, S.; Mora-Romero, U.; Maldonado-Mortera, A.K.; Torre-Bouscoulet, L. Variability of FeNO in healthy subjects at 2240 meters above sea level. J. Clin. Monit. Comput. 2016, 30, 445-449. [CrossRef] [PubMed]

16. Mattes, J.; Moeller, C.; Moseler, M.; Brandis, M.; Kuehr, J. Circadian variation of exhaled nitric oxide and urinary eosinophil protein X in asthmatic and healthy children. Pediatr. Res. 2002, 51, 190-194. [CrossRef]

17. Barański, K.; Zejda, J.E. Between-occasion repeatability of fractional exhaled nitric oxide measurements in children. J. Bras. Pneumol. 2018, 44, 52-54. [CrossRef]

18. Pijnenburg, M.W. The role of FeNO in predicting asthma. Front. Pediatr. 2019, 7, 41. [CrossRef]

19. Dreßler, M.; Salzmann-Manrique, E.; Zielen, S.; Schulze, J. Exhaled NO as a predictor of exercise-induced asthma in cold air. Nitric Oxide 2018, 76, 45-52. [CrossRef] 
20. Johansson, H.; Norlander, K.; Alving, K.; Hedenström, H.; Janson, C.; Malinovschi, A.; Nordang, L.; Emtner, M. Exercise test using dry air in random adolescents: Temporal profile and predictors of bronchoconstriction. Respirology 2016, 21, 289-296. [CrossRef]

21. Stensrud, T.; Stang, J.; Thorsen, E.; Bråten, V. Exhaled nitric oxide concentration in the period of 60 min after submaximal exercise in the cold. Clin. Physiol. Funct. Imaging 2016, 36, 85-91. [CrossRef] [PubMed]

22. Prossegger, J.; Huber, D.; Grafetstätter, C.; Pichler, C.; Braunschmid, H.; Weisböck-Erdheim, R.; Hartl, A. Winter Exercise Reduces Allergic Airway Inflammation: A Randomized Controlled Study. Int. J. Environ. Res. Public Health 2019, 16, 2040. [CrossRef] [PubMed]

23. Sachs-Olsen, A.; Berntsen, S.; Lødrup Carlsen, K.C.; Anderssen, S.A.; Mowinckel, P.; Carslen, K.H. Time spent in vigorous physical activity is associated with increased exhaled nitric oxide in non-asthmatic adolescents. Clin. Respir. J. 2013, 7, 64-73. [CrossRef]

24. Kocot, K.; Barański, K.; Melaniuk-Wolny, E.; Zajusz-Zubek, E.; Kowalska, M. Acute FeNO and Blood Pressure Responses to Air Pollution Exposure in Young Adults during Physical Activity. Int. J. Environ. Res. Public Health 2020, 17, 9012. [CrossRef] [PubMed]

25. Berhane, K.; Zhang, Y.; Linn, W.S.; Rappaport, E.B.; Bastain, T.M.; Salam, M.T.; Islam, T.; Lurmann, F.; Gilliland, F.D. The effect of ambient air pollution on exhaled nitric oxide in the Children's Health Study. Eur. Respir. J. 2011, 37, 1029-1036. [CrossRef] [PubMed]

26. Nystad, W.; Samuelsen, S.O.; Nafstad, P.; Langhammer, A. Association between level of physical activity and lung function among Norwegian men and women: The HUNT study. Int. J. Tuberc. Lung Dis. 2006, 10, 1399-1405. [PubMed]

27. Holmen, T.L.; Barrett-Connor, E.; Clausen, J.; Holmen, J.; Bjermer, L. Physical exercise, sports, and lung function in smoking versus nonsmoking adolescents. Eur. Respir. J. 2002, 19, 8-15. [CrossRef]

28. Smith, M.P.; von Berg, A.; Berde, D.; Bauer, C.P.; Hoffmann, B.; Koletzko, S.; Nowak, D.; Heinrich, J.; Schulz, H. Physical activity is not associated with spirometric indices in lung-healthy German youth. Eur. Respir. J. 2016, 48, 428-440. [CrossRef]

29. Durmic, T.; Lazovic, B.; Djelic, M.; Lazic, J.S.; Žikić, D.; Zugic, V.; Dekleva, M.; Mazic, S. Sport-specific influences on respiratory patterns in elite athletes. J. Bras. Pneumol. 2015, 41, 516-522. [CrossRef] [PubMed]

30. Dweik, R.A.; Boggs, P.B.; Erzurum, S.C.; Irvin, C.G.; Leigh, M.W.; Lundberg, J.O.; Olin, A.-C.; Plummer, A.L.; Taylor, D.R. An official ATS clinical practice guideline: Interpretation of exhaled nitric oxide levels (FENO) for clinical applications. Am. J. Respir. Crit. Care Med. 2011, 184, 602-615. [CrossRef] 